\title{
From Clinical Presentation to the Outcome: the Natural History of PML in a Portuguese Population of HIV Infected Patients
}

\author{
Filipe Nery ${ }^{\mathrm{a}, \mathrm{b}}$, Margarida Franca ${ }^{\mathrm{a}}$, Isabel Almeida ${ }^{\mathrm{a}}$, Carlos Vasconcelos ${ }^{\mathrm{a}}$
}

\begin{abstract}
Background: Progressive multifocal leukoencephalopathy (PML) is a demyelinating disease of the central nervous system, associated with immunosuppression states. As there are only some nonpublished documents concerning PML in HIV infected patients in Portugal, we pretend to characterize natural history of PML infection in a population of HIV patients.
\end{abstract}

Methods: We retrospectively reviewed, from 1992 to 2009, PML cases in a population of $724 \mathrm{HIV}$ infected patients followed in our institution. Clinical, biological, imagery features and outcomes were characterized.

Results: Twenty-five (3.45\%) patients were identified as having PML. The mean time between HIV and PML diagnosis was 20.4 months. PML was the presentation of HIV infection in $40 \%$ of the patients, and $92 \%$ had CD4 T cell count lower than 200/mm3. Paresis was the most common clinical presentation. No specific characteristics were found in cerebrospinal fluid and JCV DNA was positive in 3 of 7 patients. MRI revealed characteristic findings. Combined antiretroviral therapy was started or changed in $96 \%$ of the patients. Neurological condition got worse in 12 patients. From the 14 deaths, 5 were directly attributed to PML progression. Follow-up was lost in 8 patients.

Conclusions: PML was the presentation of HIV infection in more than $1 / 3$ of patients, frequently associated with advanced immunocompromise. MRI sensitivity to PML is high, and JCV DNA determination in CSF was not revealed to be sensible. PML diagnosis should be taken into account in HIV patients presenting any neurological symptoms, and HIV infection should be suspected when radiological findings suggest PML lesions even in previously healthy individuals.

\footnotetext{
Manuscript accepted for publication January 27, 2011

${ }^{\mathrm{a}}$ Clinical Immunology Unit, Centro Hospitalar do Porto - Hospital Sto Antonio, Porto, Portugal

${ }^{\mathrm{b}}$ Corresponding author: Filipe Nery, Largo Prof. Abel Salazar 4099-001

Porto, Portugal. Email: filipegaionery@gmail.com
}

doi:10.4021/jocmr501w
Keywords: Progressive multifocal leukoencephalopathy; JC virus; Human immunodeficiency virus; Demyelinating disease

\section{Introduction}

Progressive multifocal leukoencephalopathy (PML) is a virus-induced demyelinating disease of the central nervous system, first described in 1958 by Astrom et al [1]. It has been described in different immune compromised states, typically with suppressed cellular immunity. It also occurs in immunosuppressed patients while in treatment to lymphoma and solid organ malignancies, solid organ transplant recipients, rheumatologic diseases and a variety of diseases under biologic treatment like natalizumab or rituximab [2-5]. In the 1980s, PML became an AIDS defining illness, and it is believed that nowadays $80 \%$ or more of reported PML patients are HIV positive [6,7].

PML arises in a patient previously infected with John Cunningham virus (JCV), a polyomavirus. Primary infection occurs commonly during childhood or adolescence, and adult seroprevalence for JCV varies between 50 to $90 \%$ [810]. During immunosuppression, JCV can reactivate, resulting in lytic infection of oligodendrocytes in the brain and abortively infects astrocytes. Oligodendrocyte death results in demyelination and consequently a form of disease presentation that varies between patients, depending on the location of the underlying lesions [11]. Clinical presentation may be an insidious onset of cognitive impairment, weakness, visual field abnormalities, dysarthria, gait ataxia, dysphagia, peripheral neuropathy, dementia, seizures, behavioural changes and variable degrees of paresis $[2,9,11,12]$.

PML diagnosis relies on clinical presentation, neuroimaging, detection of JCV DNA in cerebrospinal fluid (CSF) and, eventually, in histological features whenever a stereotactic biopsy is done. Magnetic resonance imaging (MRI) is the gold standard neuroimaging diagnostic tool, showing typically high signal intensity areas on $\mathrm{T} 2 \mathrm{w}$ sequence and low intensity areas on $\mathrm{T} 1 \mathrm{w}$ sequence, without enhancement post intravenous contrast injection [13]. The presence of JCV DNA in the central nervous system (CNS), demonstrat- 
ed by PCR technique, can make the final diagnosis when the clinical presentation and imagery are typical, although there is evidence that JCV can be found in CSF of HIV infected patients without PML [14, 15]. Cortical demyelinating lesions are an integral component of the pathologic process in PML, and the findings in brain biopsy of bizarre astrocytes make the final diagnosis $[7,11]$.

PML in HIV infected patients has a poor prognosis, and continues to be one of the deadliest opportunistic infections. Treatment of these patients remains on highly active antiretroviral therapy (HAART), based on the evidence that lowering viral HIV load, and consequently giving rise to the CD4 count, will conduct to a more effective immune defense of the host. The outcome of the patients with PML in the setting of HIV is better when HAART is started [16-18]. When associated with HAART, cidofovir might improve the outcome of the patients [19].

The aim of the study was to analyze the natural history of PML in HIV infected patients followed in our institution, from the clinical presentation features to the outcomes.

\section{Patients and Methods}

We retrospectively reviewed an HIV population followed in our hospital between 1992 and 2009, identified as having had PML. Diagnosis of PML was based on clinical presentation, imaging, JCV PCR in CSF and biopsy findings whenever done. Data was collected as follows: HIV load, CD4 count, time between HIV and PML diagnosis, CSF biochemical and cytological characteristics, previous AIDS defining diseases, clinical presentation, imagery findings, CSF JCV PCR, brain biopsy, therapy instituted and clinical course. Statistical analysis was computed in SPSS version 17.0.

\section{Results}

Twenty-five patients were considered eligible, as having had PML in the context of HIV infection, collected from a population of $724 \mathrm{HIV}$ positive patients. Four were female $(16 \%)$ and 21 were male $(84 \%)$. HIV route of transmission was mainly sexual ( $56 \%$ of patients), followed by intravenous drug abuse $(40 \%)$. In one patient, HIV transmission was attributed to bone marrow (BM) transplant in 1984. All of the 25 patients were infected with the HIV-1, and one of them had also concomitant HIV-2 infection. Eight patients (32\%) were co-infected with HCV. The mean age at HIV diagnosis was 36.4 years. On average, 20.4 months after HIV diagnosis, the patients were diagnosed with PML, but with a median time of 0.75 months, due to the fact that there were cases (11 patients) with both diagnoses being made simultaneously (in $44 \%$ of the cases).

CD4 count was always available at the time of HIV di- agnosis. Mean CD4 count at the time of PML presentation was of $122 / \mathrm{mm}^{3}$, but a notion of a consistent lower immunosuppression state is expressed by a median of $73 / \mathrm{mm}^{3}$. Twenty-three patients had CD4 count lower than $200 / \mathrm{mm}^{3}$ and two patients had CD4 count above $500 / \mathrm{mm}^{3}$. Only patients with PML diagnosis after 1997 (10) had HIV viral load determined, with a mean of 117951 copies/ $\mu 1$. Only one had less than 50 copies $/ \mathrm{ml}$. Six patients were under any sort of antiretroviral therapy.

Clinical presentation varied between patients, as expressed in Table 1. Motor disorders with paresis were the most common feature presentation (72\%), and mainly unilateral (88.9\%). Speech disorders (dysarthria, dysphasia and dyspraxia) and cognitive and behavioural disturbance followed motor disturbance, in $36 \%$ and $24 \%$ of the patients, respectively.

Lumbar punction was done in 19 patients. Cytology was done in all of them and biochemistry with glucose and protein analysis in 18 patients. In 6 patients leukocyte count was above the normal value, and always due to mononuclear cells. Only one patient was found to have low glucose CSF levels, and six patients, high protein levels. In all of the 19 patients that underwent CSF analysis, Gram stain was negative as was the cultural exam. JCV was searched only once in 6 patients, being positive in 2 of them. In another patient, the first four out of five determinations were negative.

All patients had brain-CT, showing hypodense lesions in the cerebral white matter, with lack of contrast enhancement in $88 \%$ of the cases.

Brain MRI was done in 16 patients, in all confirming the diagnosis, presenting characteristic findings, with T2weighted hyperintense lesions in cerebral white matter, with hypoattenuated corresponding lesions in T1-w. The three patients with normal Brain CT scans had abnormalities in MRI, one of them with definite PML diagnosis.

Only four brain biopsies were done (patients 15, 20, 22 and 23), showing abundant macrophages, bizarre astrocytes and with nuclear inclusions in some of the cells, all samples compatible with PML diagnosis. In one of the patients ( $\mathrm{pt}$ 15), in spite of definite PML diagnosis based on the histological finding, PCR in CSF was negative.

Therapy was continued, changed or initiated in 24 patients by the time of PML diagnosis. Before 1995 all diagnosis but one were treated with zidovudine (AZT). Age at the time of HIV and PML diagnosis, before and after introduction of cARV is expressed in Table 2.

After 1997, in spite of therapy started (or continued), in 10 patients there was a worsening of the clinical condition. Total recovery of the neurological deficits happened in only two patients (one died in a car accident, another was alive after 135 months of follow-up). Fourteen patients are known to be already dead, 5 of them due to PML progression, the others were attributed to other infections, mainly respiratory. Eight patients were lost in the follow-up. 


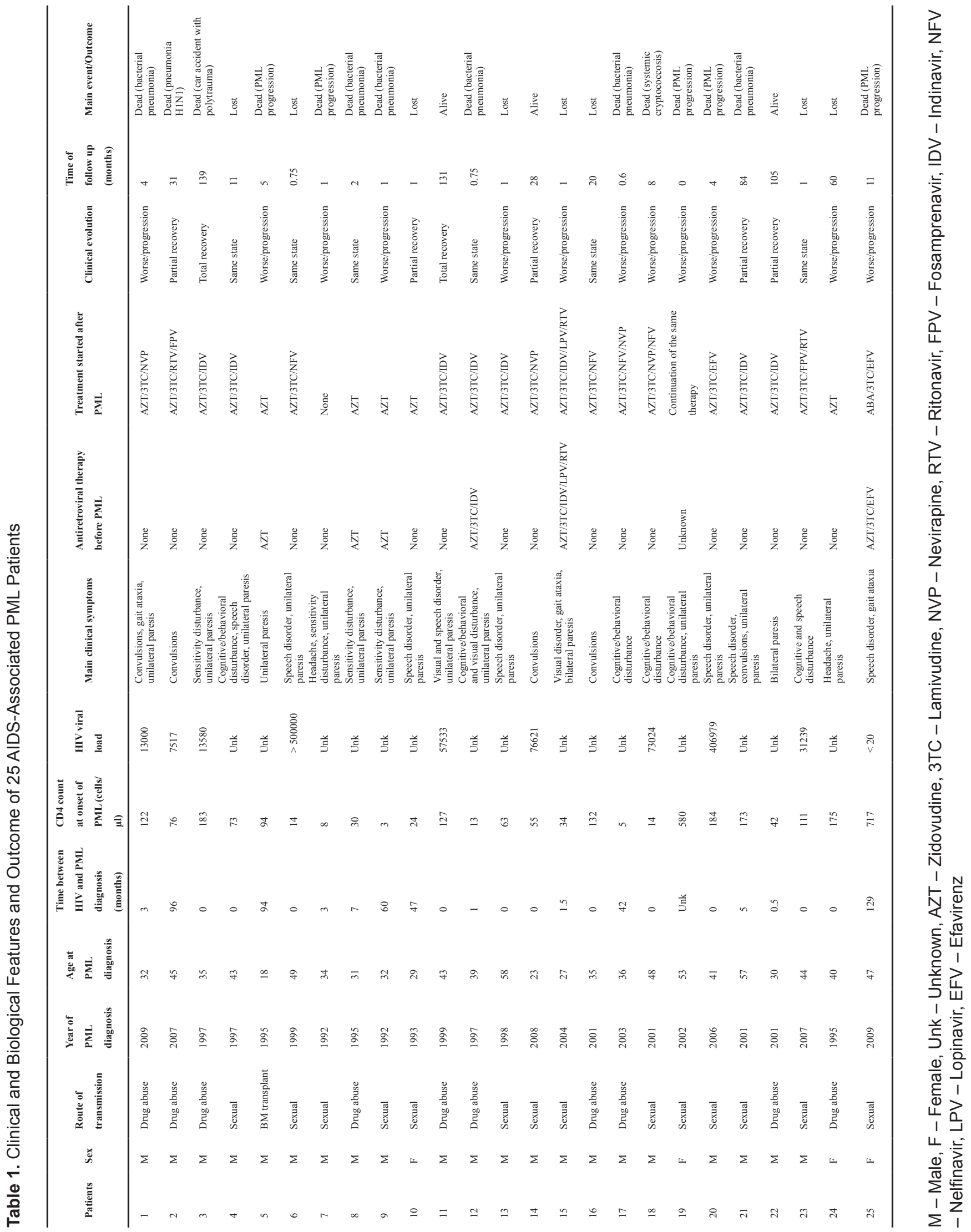


Table 2. Differences Between Pre-HAART and Post-HAART Era Concerning CD4 T Cell Count, Age of Diagnosis (PML and HIV) and Death Causes

\begin{tabular}{|c|c|c|c|}
\hline \multirow{2}{*}{ Characteristic } & \multirow{2}{*}{ All $(n=25)$} & \multicolumn{2}{|l|}{ PML diagnosis } \\
\hline & & Before $1997(n=6)$ & $1997-2009(n=19)$ \\
\hline Gender & 4 female, 21 male & 2 female, 4 male & 2 female, 17 male \\
\hline CD4+ cell count at diagnosis, median (IQR), cell/ $\mu 1$ & $73(19-152.5)$ & $27(6.75-114.25)$ & $76(34-173)$ \\
\hline Age at HIV diagnosis, median (IQR), years & $35.5(30.25-43.0)$ & $29(20.75-34.75)$ & $37.5(32.75-45)$ \\
\hline Age at PML diagnosis, median (IQR), years & $39.0(31.5-46.0)$ & $31.5(26.25-31.5)$ & $43.0(35.0-48.0)$ \\
\hline $\begin{array}{l}\text { Time between HIV and PML diagnosis, median (IQR), } \\
\text { months }\end{array}$ & $0.75(0.0-33.25)$ & $27.0(2.25-68.5)$ & $0.0(0-3.5)$ \\
\hline Death (all causes) & 14 & 4 & 10 \\
\hline Death (attributed to PML progression) & 5 & $2(50 \%)$ & $3(30 \%)$ \\
\hline
\end{tabular}

\section{Discussion}

In this case series we describe twenty-five HIV patients diagnosed with PML from 1992 to 2009 among 724 HIV patients, representing a PML prevalence, in the population considered, of $3.45 \%$, concordant to that described in the literature $[11,12,20]$.

HIV route of transmission of our patients is similar to that reported by the Portuguese National Coordination for HIV infection/AIDS till the end of the year 2009: 40\% by intravenous drug use and $56 \%$ by sexual route [21].

PML diagnosis was the presentation of HIV infection in eleven (44\%) patients. The median CD4 count in our population was $73 / \mathrm{mm}^{3}$, similar to that described in recent retrospective large studies [22]. In spite of that, two patients had a CD4 count above $500 / \mathrm{mm}^{3}$ - although a rare finding, it has already been previously described [23]. In one of those patients, PML diagnosis was probable and, in the other one, it was necessary to perform several lumbar punctions before a positive result appeared. It may be justified because techniques for determination of JCV PCR are less sensitive in patients under cARV [24].

Clinical features are quite different between patients and, although motor disorders were the most common findings, neurological presentation varied according to the cerebral region most affected by JCV infection, as expressed by imagery. As expected, CSF analysis, when performed, did not reveal any specific characteristics $[25,26]$. JCV DNA determination by PCR was done in 7 patients, being positive in three of them (42.9\%). There was a false negative determination in a patient with characteristic findings in MRI and histological confirmation of JCV infection. In seems that the analysis for JCV DNA early in the course of the disease may sometimes show a negative result, and that with lower immunological states, the probability of having a positive result for JCV DNA in CSF is higher [15, 26]. Three patients that were JCV positive had a CD4 count scarcely elevated than those that were JCV negative. Probably, using techniques of real-time PCR, and rising the cycling in the protocol, detection level of JCV DNA would be higher, elevating the sensitivity of the exam and diminishing the number of false negatives.

All the patients underwent a CT scan, and MRI was done in sixteen of them. Three CT scans were normal, but MRI showed characteristic findings of T2-weighted hyperintense lesions in cerebral white matter, with hypoattenuated corresponding lesions in T1-w, without mass effect, even in those patients in which CT scan was normal. MRI is the preferred imagery diagnostic tool for JCV infection, showing specific signs [13].

Antiretroviral therapy has been changing dramatically since late 1990s. This retrospective study also shows an historic perspective of antiretroviral therapy in Portugal (as it was in the most western countries). AZT was the first antiviral agent used for HIV treatment, and it is still used nowadays. It is still recommended as one of the agents to be included in therapeutic scheme due to its good penetration in CNS.

In pre-HAART era (before 1997), 3 patients diagnosed with PML were already on AZT and continued this therapy. Another two patients started on AZT. Of these five patients treated with AZT, two were lost from follow-up and the other three died. Before 1997, AZT monotherapy was definitely not an option, as was already outlined in the early 1990s [27].

We noticed that age at the moment of HIV (and subsequently PML) diagnosis is rising in the last years (cut-off being the beginning of cARV era), probably due to a change of risk behaviours for HIV transmission, as is well described elsewhere [28].

Eight patients were lost in follow-up. In the remaining 
seventeen patients, five died due to PML progression, nine died due to other causes and only three are still alive, one of them with total recovery and the others with partial neurological recovery.

The median time to PML-attributable death was 4.2 months, compared with 30.04 months for other-cause mortality. Patients that do not respond to treatment have a rapid course to death with a high morbidity conferred by the progression of neurological deficits. One fragility attributed to this paper, due to its retrospective character, is the loss in the follow-up of a considerable number of patients, attributed to the abandonment as well as the transfer to other institutions, concerning the residence area of the patient, what leads to an incapacity to accurately extrapolate survival rates.

In conclusion, PML among HIV infected patients, in spite of its low prevalence, must be considered whenever an HIV patient presents with neurological symptoms independently of which ones, and mainly when a lower immunosuppression state as expressed by a low CD4 count is known. When a patient presents with neurological symptoms and PML characteristic findings in MRI, an HIV test should be performed. More than one CSF sample should be performed to JCV DNA analysis if the first sample is negative. That should be done in patients under cARV, as well in those with high CD4 T cell count. PML is an AIDS defining illness that occurs more often with a CD4 count lower than $200 / \mathrm{mm}^{3}$. When the cause of death is PML progression, it is rapid, arising in few months, in spite of cARV started at the time of diagnosis. Finally, PML in the post-HAART era still leads to great morbimortality. It can appear even with high CD4 counts and undetectable viremia.

\section{Conflict of Interest}

There is no conflict of interest.

\section{References}

1. Astrom KE, Mancall EL, Richardson EP, Jr. Progressive multifocal leuko-encephalopathy; a hitherto unrecognized complication of chronic lymphatic leukaemia and Hodgkin's disease. Brain 1958;81(1):93-111.

2. Epker JL, van Biezen P, van Daele PL, van Gelder T, Vossen A, van Saase JL. Progressive multifocal leukoencephalopathy, a review and an extended report of five patients with different immune compromised states. Eur J Intern Med 2009;20(3):261-267.

3. Shitrit D, Lev N, Bar-Gil-Shitrit A, Kramer MR. Progressive multifocal leukoencephalopathy in transplant recipients. Transpl Int 2005;17(11):658-665.

4. Boren EJ, Cheema GS, Naguwa SM, Ansari AA, Ger- shwin ME. The emergence of progressive multifocal leukoencephalopathy (PML) in rheumatic diseases. J Autoimmun 2008;30(1-2):90-98.

5. Carson KR, Evens AM, Richey EA, Habermann TM, Focosi D, Seymour JF, Laubach J, et al. Progressive multifocal leukoencephalopathy after rituximab therapy in HIV-negative patients: a report of 57 cases from the Research on Adverse Drug Events and Reports project. Blood 2009;113(20):4834-4840.

6. Koralnik IJ, Schellingerhout D, Frosch MP. Case records of the Massachusetts General Hospital. Weekly clinicopathological exercises. Case 14-2004. A 66-yearold man with progressive neurologic deficits. N Engl J Med 2004;350(18):1882-1893.

7. Moll NM, Rietsch AM, Ransohoff AJ, Cossoy MB, Huang D, Eichler FS, Trapp BD, et al. Cortical demyelination in PML and MS: Similarities and differences. Neurology 2008;70(5):336-343.

8. Egli A, Infanti L, Dumoulin A, Buser A, Samaridis J, Stebler C, Gosert R, et al. Prevalence of polyomavirus $\mathrm{BK}$ and $\mathrm{JC}$ infection and replication in 400 healthy blood donors. J Infect Dis 2009;199(6):837-846.

9. Jiang M, Abend JR, Johnson SF, Imperiale MJ. The role of polyomaviruses in human disease. Virology 2009;384(2):266-273.

10. Zheng HC, Yan L, Cui L, Guan YF, Takano Y. Mapping the history and current situation of research on John Cunningham virus - a bibliometric analysis. BMC Infect Dis 2009;9:28.

11. Tyler KL. The uninvited guest: JC virus infection of neurons in PML. Neurology 2003;61(6):734-735.

12. Zunt JR, Tu RK, Anderson DM, Copass MC, Marra CM. Progressive multifocal leukoencephalopathy presenting as human immunodeficiency virus type 1 (HIV)-associated dementia. Neurology 1997;49(1):263-265.

13. Sarrazin JL, Soulie D, Derosier C, Lescop J, Schill H, Cordoliani YS. [MRI aspects of progressive multifocal leukoencephalopathy]. J Neuroradiol 1995;22(3):172179.

14. Eggers C, Stellbrink HJ, Buhk T, Dorries K. Quantification of JC virus DNA in the cerebrospinal fluid of patients with human immunodeficiency virus-associated progressive multifocal leukoencephalopathy--a longitudinal study. J Infect Dis 1999;180(5):1690-1694.

15. Hammarin AL, Bogdanovic G, Svedhem V, Pirskanen R, Morfeldt L, Grandien M. Analysis of PCR as a tool for detection of JC virus DNA in cerebrospinal fluid for diagnosis of progressive multifocal leukoencephalopathy. J Clin Microbiol 1996;34(12):2929-2932.

16. Falco V, Olmo M, del Saz SV, Guelar A, Santos JR, Gutierrez M, Colomer D, et al. Influence of HAART on the clinical course of HIV-1-infected patients with progressive multifocal leukoencephalopathy: results of an observational multicenter study. J Acquir Immune Defic 
Syndr 2008;49(1):26-31.

17. Clifford DB, Yiannoutsos C, Glicksman M, Simpson DM, Singer EJ, Piliero PJ, Marra CM, et al. HAART improves prognosis in HIV-associated progressive multifocal leukoencephalopathy. Neurology 1999;52(3):623625.

18. Engsig FN, Hansen AB, Omland LH, Kronborg G, Gerstoft J, Laursen AL, Pedersen C, et al. Incidence, clinical presentation, and outcome of progressive multifocal leukoencephalopathy in HIV-infected patients during the highly active antiretroviral therapy era: a nationwide cohort study. J Infect Dis 2009;199(1):77-83.

19. Zimmermann T, Stingele K, Hartmann M, Haas J, von Einsiedel R, Wildemann B. Successful treatment of aids related PML with HAART and cidofovir. Eur J Med Res 2001;6(5):190-162.

20. Taoufik Y, Gasnault J, Karaterki A, Pierre Ferey M, Marchadier E, Goujard C, Lannuzel A, et al. Prognostic value of JC virus load in cerebrospinal fluid of patients with progressive multifocal leukoencephalopathy. J Infect Dis 1998;178(6):1816-1820.

21. http://www.sida.pt.

22. Khanna N, Elzi L, Mueller NJ, Garzoni C, Cavassini M, Fux CA, Vernazza P, et al. Incidence and outcome of progressive multifocal leukoencephalopathy over 20 years of the Swiss HIV Cohort Study. Clin Infect Dis 2009;48(10):1459-1466.

23. Delobel P, Brassat D, Delisle MB, Scaravilli F, Clanet M. Progressive multifocal leukoencephalopathy in an HIV patient with normal CD4 T-cell count and magnetic resonance imaging. AIDS 2004;18(4):702-704.

24. Cinque P, Koralnik IJ, Gerevini S, Miro JM, Price RW. Progressive multifocal leukoencephalopathy in HIV-1 infection. Lancet Infect Dis 2009;9(10):625-636.

25. Berger JR, Kaszovitz B, Post MJ, Dickinson G. Progressive multifocal leukoencephalopathy associated with human immunodeficiency virus infection. A review of the literature with a report of sixteen cases. Ann Intern Med 1987;107(1):78-87.

26. Wang Y, Kirby JE, Qian Q. Effective use of JC virus PCR for diagnosis of progressive multifocal leukoencephalopathy. J Med Microbiol 2009;58(Pt 2):253-255.

27. Garrote FJ, Molina JA, Lacambra C, Mollejo M, Madero S, del Ser T. [The inefficacy of zidovudine (AZT) in progressive multifocal leukoencephalopathy (PML) associated with the acquired immunodeficiency syndrome (AIDS)]. Rev Clin Esp 1990;187(8):404-407.

28. Manfredi R. HIV infection and advanced age emerging epidemiological, clinical, and management issues. Ageing Res Rev 2004;3(1):31-54. 